\title{
ERRATUM
}

Vijaya Krishnamoorthy • Mark L. Latash •

John P. Scholz • Vladimir M. Zatsiorsky

\section{Muscle synergies during shifts of the center of pressure by standing persons}

Published online: 28 January 2004

C) Springer-Verlag 2004

\section{Exp Brain Res (2003) 152:281-292}

This article was erroneously published under the section Review. In fact it is a Research Article.

The online version of the original article can be found at http://dx. doi.org/10.1007/s00221-003-1574-6

V. Krishnamoorthy · M. L. Latash $(\bowtie) \cdot$ V. M. Zatsiorsky

Department of Kinesiology, Rec. Hall - 267L, The

Pennsylvania State University,

University Park, PA 16802, USA

e-mail: mll11@psu.edu

\section{J. P. Scholz}

Department of Physical Therapy and Biomechanics and Movement Science Program, University of Delaware,

Newark, DE 19716, USA 